\title{
INTEGRANDO EDUCAÇÃO E TRABALHO: O CASO DO PERMANECER SUS DA SECRETARIA DA SAÚDE DO ESTADO DA BAHIA
}

\author{
INTEGRATING EDUCATION AND WORK:THE CASE OF "PERMANECER SUS" (REMAIN UHS), OF THE \\ STATE DEPARTMENT OF HEALTH OF BAHIA
}

\author{
INTEGRANDO EDUCACIÓN Y TRABAJO: EL CASO DEL PERMANECER SUS DE LA SECRETARÍA DE \\ SALUD DEL ESTADO DE BAHÍA
}

\author{
Wilton Nascimento Figueredo ${ }^{1}$ \\ Renata Meira Véras ${ }^{2}$
}

Resumo Este artigo teve por objetivo analisar as contribuições do Permanecer SUS, programa da Secretaria da Saúde do Estado da Bahia, para a formação dos estudantes e futuros profissionais de saúde. A pesquisa teve abordagem qualitativa na perspectiva da etnografia institucional. Os dados foram obtidos por meio de entrevistas semiestruturadas com vinte estudantes de saúde participantes do programa em 2015. Os resultados apontaram para a efetividade do Permanecer SUS. Constataram-se a valorização do trabalho em equipe de forma interdisciplinar, a desarticulação de redes e a necessidade de abordagens na formação desses estudantes acerca da humanização e do acolhimento. Em contrapartida, verificou-se deficiência na compreensão de rede por parte dos profissionais de saúde já atuantes da unidade, o que pode dificultar uma assistência integral. Concluiu-se que o programa Permanecer SUS oportuniza o diálogo, a ressignificação da formação e a comunicação entre os integrantes e futuros profissionais de saúde, estimulando os estudantes a trabalharem em redes no Sistema Único de Saúde.

Palavras-chave educação em saúde; acolhimento; humanização da assistência; educação superior.
Abstract This article aimed to analyze the contributions made by "Permanecer SUS" (Remain UHS), a State Department of Health of Bahia (Brazil) program for training students and future health professionals. The study was conducted based on a qualitative approach from the institutional ethnography perspective. Data were obtained through structured interviews carried out with twenty health students participating in the program in 2015. The results showed the effectiveness of the Permanecer SUS (Remain UHS) program. The study found there is a need to value interdisciplinary teamwork, to dismantle networks, and the need for approaches to train these students in humanization and acceptance. In contrast, it was found there is a lack of understanding on networks among health professionals already working at the unit, something that can hinder comprehensive care. It was concluded that the Permanecer SUS (Remain UHS) program provides opportunities for dialog, reinterpretation of training, and for communications among team members and future health professionals, encouraging students to work in networks in the Unified Health System.

Keywords health education; welcoming; humanization of care; higher education. 


\section{Introdução}

Abordar a questão da integração educação e trabalho na saúde é adentrar em uma discussão sobre a formação dos profissionais de saúde. Compreende-se por integração educação e trabalho um processo dinâmico e interativo que envolve estudantes, docentes, trabalhadores e gestores dos serviços, visando à qualidade, à resolubilidade e à atenção de redes para responder às necessidades dos usuários de saúde (Carvalho e Ceccim, 2012).

Ao se observar a história das políticas educacionais, nota-se que a educação superior em saúde nem sempre esteve orientada para a integração entre ensino e trabalho, não priorizando o estímulo de competências necessárias para o enfrentamento de saúde da população e do avanço do Sistema Único de Saúde (SUS) (Carvalho e Ceccim, 2012). Mesmo diante dos avanços no ensino dos profissionais de saúde, o que se tem visto é uma formação baseada em conceitos, teorias e na racionalidade dos processos, muito aquém de uma formação direcionada para a integralidade do cuidado. Noção que emerge a partir do momento em que a saúde foi garantida como direito de todos e dever do Estado, por meio da Constituição Federal de 1988 (Brasil, 1988).

Para Mattos (2004, p. 1.412), a integralidade consubstancia-se como um "atendimento integral, com prioridade para as atividades preventivas, sem prejuízo dos serviços assistenciais". Ao mesmo tempo, Ghizoni, Arruda e Tesser (2010, p. 831) consideram que a formação do pessoal de saúde deve se respaldar nessa perspectiva, buscando "a ruptura não só com o modelo tradicional de formação", mas também implicando a reconstrução dos significados e das práticas profissionais.

Entretanto, principalmente entre as décadas de 1950 e 1980, o investimento do Estado e dos gestores políticos obteve forte direcionamento para o financiamento e a organização da assistência à saúde, distanciando-se do incentivo à formação dos profissionais de saúde na concepção da integralidade do cuidado. A questão de recursos humanos em saúde (RHS), no referido período, “ainda que tivesse presente na retórica como fundamental, não se traduzia em foco de atenção vinculada à organização da produção do próprio trabalho na sociedade" (Brasil, 2011a, p. 11). Assim, o ensino em saúde foi "voltado para a prática hospitalar e médico-centrada (...) que não contempla todas as necessidades básicas da população" (Ghizoni, Arruda e Tesser, 2010, p. 831).

Nesse sentido, a partir da década de 1980, emergiram movimentos com o objetivo de melhor estruturar e garantir saúde integral para os cidadãos brasileiros. Dessas mobilizações culminou a $8^{a}$ Conferência Nacional de Saúde, em 1986, que dentre as suas principais pautas defendia a saúde como direito, a reformulação do sistema e o financiamento de saúde. Ao mesmo tempo, as discussões nessa conferência orientaram a $1^{\text {a }}$ Conferência Nacional Temática de Recursos Humanos em Saúde, organizada também em 1986. Entre seus 
três principais núcleos temáticos, destacou-se “a preparação de recursos humanos, enfocada sob a ótica da formação e aprimoramento de pessoal dos níveis médio e elementar, ensino de graduação e pós-graduação, educação continuada e integração docente-assistencial" (Brasil, 201 la, p. 12).

É possível salientar que a $8^{\text {a }}$ Conferência Nacional de Saúde e a $1^{\text {a }}$ Conferência Nacional Temática de Recursos Humanos em Saúde tenham contribuído para a operacionalização dos artigos 196 e 200 da Constituição Federal de 1988, já que passaram a responsabilizar o Estado pela capacitação, pelo preparo e pela formação de recursos humanos para o SUS (Brasil, 1988).

A partir da lei n. 8.080/90 - especificamente capítulo IV, artigo 27, que versa sobre responsabilidade das três esferas do governo (federal, estadual e municipal) em organizar e articular programas de aperfeiçoamento de pessoal, em todos os níveis, para a efetivação da política de RHS (Brasil, 1990)foram criadas a Norma Operacional Básica (NOB) e a Norma Operacional de Assistência à Saúde (Noas), com o objetivo de efetivar as novas atribuições do processo de implementação do SUS. Destacam-se a NOB/SUS, a Noas/SUS e a NOB/RH/SUS. As duas primeiras "pouco auxiliaram na organização da área de recursos humanos nas três esferas de gestão" (Brasil, 201la, p. 23). Entretanto, a NOB/RH/SUS contribuiu, em 2003, para que o Ministério da Saúde criasse a Secretaria de Gestão do Trabalho e da Educação na Saúde (SGTES), funcionando em dois departamentos: o Departamento de Gestão e da Regulação do Trabalho na Saúde (Degerts) e o Departamento de Gestão da Educação na Saúde (Deges).

Concomitantemente, no mesmo ano de 2003 foi criada a Política Nacional de Humanização (PNH), com base nas reivindicações do povo brasileiro. Seus principais objetivos buscavam enfrentar as disparidades no atendimento, na qualidade e na dignidade do cuidado em saúde, além de estimular iniciativas de humanização no SUS, mediante a organização e a gestão do trabalho para a produção do cuidado pelos trabalhadores de saúde (Brasil, 2008).

Assim, diante das diretrizes da $1^{\text {a }}$ Conferência Nacional Temática de Recursos Humanos em Saúde e da PNH, a SGTES, buscando o aprimoramento da qualificação dos profissionais de saúde e uma consequente mudança no perfil desses trabalhadores, instituiu diversas políticas e programas, a exemplo do Vivências e Estágios na Realidade do Sistema Único de Saúde (VER-SUS 2004), Programa Nacional de Reorientação da Formação Profissional em Saúde (Pró-Saúde - 2005), Política Nacional de Educação Permanente em Saúde (PNEPS 2007) e Programa de Educação pelo Trabalho para a Saúde (PET-Saúde - 2010), para responder à população e efetivar os princípios e diretrizes do SUS (Brasil, 2011 b). Contudo, sozinha a SGTES não conseguiria dar conta de todas as necessidades no campo da educação e do trabalho, por isso a descentralização e a regionalização das ações nessas duas vertentes foram intensificadas e estimuladas em cada secretaria estadual e municipal. 
Nessa perspectiva, a Política Estadual de Gestão do Trabalho e Educação na Saúde (PEGTES) foi desenvolvida pela Secretaria da Saúde do Estado da Bahia (Sesab) em 2007 e revisada em 2012, por meio da Superintendência de Recursos Humanos da Saúde (SUPERH). Durante a criação da PEGTES, diversos atores como o Conselho Estadual de Secretários Municipais de Saúde da Bahia (Cosems-BA), a Comissão Intergestores Bipartite (CIB), o Conselho Estadual de Saúde (CES) e instituições de ensino (públicas e privadas) (Bahia, 2012) foram incluídos na discussão, com o objetivo de efetivar a PNEPS e a política do Pró-Saúde, para provimento e compromisso institucional em mudanças significativas na gestão do trabalho e da educação em saúde (Pinto e Teixeira, 2011).

De forma sucinta, a PEGTES em seus princípios procura garantir a necessidade de investimento, por exemplo, em ações direcionadas para "o trabalho como princípio educativo, educação como prática transformadora, humanização e democratização das relações de trabalho" (Bahia, 2012, p. 13). Já em suas diretrizes específicas para a educação na saúde, estabelece a

apropriação ativa de conhecimentos e experiências que subsidiem a reorientação da formação, das práticas e dos processos de trabalho, por meio da problematização (...) e incentivo às mudanças curriculares (...) para atender às necessidades do SUS" (Bahia, 2012, p. 13).

Em razão das necessidades advindas da obrigatoriedade estatal para com a formação dos trabalhadores da saúde, foram criadas ações, projetos e programas que fomentassem o cumprimento da PEGTES, como o Mobiliza SUS (2011), o Programa Mais Futuro (2008) e o Permanecer SUS (2008). Este último é um programa que busca provocar nos estudantes uma postura ética e responsável durante seu processo de formação, por meio da vivência da realidade concreta dos processos de trabalho em saúde, por isso torna-se necessário um estudo que reflita sobre as contribuições e possibilidades para a formação do estudante da área de saúde.

O objetivo deste artigo foi, portanto, analisar as contribuições do Permanecer SUS para a formação do profissional de saúde na compreensão dos estudantes participantes do programa.

\section{O programa Permanecer SUS}

O Permanecer SUS foi instituído em 2008, integrando educação e trabalho como proposta de reorientação da formação dos estudantes de saúde para a garantia de satisfação dos usuários nas ações de assistência. Referenciado por meio da PNH e ancorado no princípio do acolhimento, objetivando a escuta 
ampliada e o acionamento de redes internas e externas nos serviços de saúde, esse programa proporciona a vivência de estudantes nas redes de atenção de urgência e emergência de instituições públicas como hospitais, maternidades e centros de referência da região metropolitana de Salvador, Bahia.

Em sua versão inicial, o programa Permanecer SUS contemplava apenas os cursos de enfermagem, medicina, psicologia e serviço social, porém, a partir de 2014 e até o fechamento deste artigo, abrange outros cursos de saúde, como o bacharelado interdisciplinar em saúde, farmácia, fonoaudiologia, fisioterapia, odontologia, nutrição e saúde coletiva de três instituições superiores de ensino: Universidade Federal da Bahia (UFBA), Universidade Estadual da Bahia (Uneb) e Universidade Católica do Salvador (UCSAL). Trata-se de um estágio extracurricular em que os estudantes selecionados recebem uma bolsa no valor de $\mathrm{R} \$ 400$ (dado referente ao ano de 2014), além de auxílio-transporte, durante seis meses, podendo ser renovada por igual período. A carga horária é semanal, de vinte horas, sendo 16 horas em prática e quatro destinadas à educação permanente. Esta é mediada pelo professor (preceptor) na unidade do estágio e envolve todos os estudantes participantes no debate de um estudo de caso, com o objetivo de promover a compreensão e o conhecimento teórico, prático e político-filosófico dos princípios básicos do SUS, no âmbito da instituição de saúde e na perspectiva da discussão interdisciplinar (Bowes, 2014).

Conforme o documento base do programa Permanecer SUS, este também se propõe a estimular a permanência na universidade de estudantes em vulnerabilidade socioeconômica (Bahia, 2008), por isso, no momento da seleção, estes têm prioridade em relação aos outros candidatos. Contudo, não se trata de uma característica de exclusão para os demais.

Por fim, desde a implantação do Permanecer SUS, em 2008, até 2013 participaram e foram capacitados 559 estudantes (Bowes, 2014).

\section{Percurso metodológico}

A pesquisa ${ }^{3}$ que deu origem a este artigo teve abordagem qualitativa, na perspectiva metodológica da etnografia institucional (EI), a qual se dedica ao conhecimento de como vêm sendo construídas e organizadas as relações sociais nas instituições, assim como o significado que as pessoas atribuem ao que vivenciam nos diversos cenários que se manifestam no interior das organizações.

Para Devault e McCoy (2002), a EI apresenta-se como um fundamento metodológico com foco prioritário no estudo das organizações institucionais, centralizadas nas experiências individuais dos sujeitos, que estão condicionados pelas relações existentes nessas instituições. É, portanto, 
uma abordagem que permite a imersão nas atividades cotidianas das relações institucionais (Campbell e Gregor, 2008).

A produção dos dados ocorreu no período compreendido entre setembro de 2013 e janeiro de 2014, em diversos dias úteis da semana, nos turnos matutino e vespertino. As técnicas de pesquisa utilizadas foram a observação participante, o diário de campo e a entrevista semiestruturada.

As observações participantes ocorreram em quatro unidades públicas conveniadas ao programa Permanecer SUS na cidade de Salvador: um centro de referência de diagnóstico, uma maternidade e dois hospitais gerais, com foco em suas emergências. A escolha dessas organizações se pautou na diferença do tipo de serviço prestado à população, por serem de grande porte e atender diariamente centenas de usuários do SUS. Para cada instituição foi despendido um tempo de, aproximadamente, um mês e 15 dias.

O diário de campo foi utilizado nas observações para registrar as informações que não foram ditas em conversas formais e até mesmo para anotações diversas que pudessem subsidiar a discussão dos dados (Véras e Morais, 2014).

As entrevistas semiestruturadas se fundamentaram em um breve levantamento sociodemográfico e econômico dos estudantes, assim como em nove questões norteadoras acerca dos objetivos do estágio, tais como conceitos sobre trabalho em equipe, acolhimento e humanização, desafios encontrados, percepção dos profissionais de saúde e usuários do programa e relevância do estágio para a formação em saúde pública. Todo esse processo, portanto, resultou no estabelecimento de conexões entre as entrevistas feitas e os diferentes ambientes institucionais da atividade dos estagiários.

As entrevistas foram gravadas em formato MP3 e transcritas no programa de textos Microsoft Word ${ }^{\circledR}$ 2013, com duração, em média, entre vinte e quarenta minutos, cada.

Os entrevistados foram estagiários do programa que, após a solicitação para a entrevista, se voluntariaram a participar deste trabalho: cinco estudantes de cada unidade conveniada, totalizando, portanto, vinte discentes. Quanto à quantidade de entrevistados, o critério utilizado foi o de saturação das informações, respaldando-se na compreensão da lógica dos diferentes atores envolvidos e no entendimento da homogeneidade do grupo (Angrosino, 2009).

Os critérios de inclusão dos participantes foram: ser maior de 18 anos, desempenhar suas atividades há pelo menos dois meses (tempo considerado, segundo a coordenação do programa, ideal para o conhecimento e a realização das atividades) e estar inserido na emergência adulta. De modo a homogeneizar os discursos e em razão de sua dinâmica diferenciada de atendimento, foram excluídos os estagiários da emergência pediátrica.

Para preservar o anonimato, os atores foram codificados com a seguinte legenda: EENF (estudante de enfermagem), ESSO (estudante de serviço so- 
cial), EFIS (estudante de fisioterapia) e assim sucessivamente para outros cursos. Além disso, foi acrescida a sequência de 1 a 20 para diferenciação por exemplo: EENFl (estudante de enfermagem 1). Ao mesmo tempo, para evitar embaraços institucionais, protegeu-se o nome das organizações de saúde visitadas. Para esse fim, mencionou-se apenas a natureza administrativa/serviço dispensado por elas, como maternidade, centro e referência ou hospital geral.

A análise dos dados seguiu três etapas: a primeira foi a leitura minuciosa do material coletado; a segunda, a identificação nas falas dos entrevistados de alguma similaridade com a temática estudada; e, por último, a fragmentação dos discursos e a criação de categorias.

Por conseguinte, utilizou-se da análise do discurso como a estratégia para interpretar o sentido que cada estagiário buscava revelar em sua expressão, além da compreensão do sentido tácito de cada palavra ou frase dita, que foi considerada diante do contexto, da complexidade e dos significados de cada alocução dos entrevistados (Foucault, 1986).

Conforme prescrito na resolução n. 466/2012 do Conselho Nacional de Saúde/Ministério da Saúde (Brasil, 2012), que estabelece parâmetros sobre as pesquisas envolvendo seres humanos, o estudo foi submetido ao Comitê de Ética e Pesquisa do Instituto de Saúde Coletiva da UFBA e aprovado de acordo com o parecer n. 002-11.

\section{Caracterização dos atores e locus da pesquisa}

Com o objetivo de caracterizar os atores do estudo, optou-se pela estratificação dos dados (Tabela 1), com uma breve descrição dos resultados encontrados e do perfil de cada instituição de saúde.

Quando analisado o discurso dos estagiários nas quatro instituições de saúde, não se encontraram grandes disparidades em suas falas, havendo uma confluência nas respostas e na forma de condução do trabalho em equipe. Em consequência, mediante o objetivo do trabalho, o referencial teórico (considerando-se os princípios norteadores da PNH e da PEGTES) e o relato dos estudantes, emergiram as três categorias: humanização e acolhimento da atenção à saúde; construindo redes; e interdisciplinaridade.

\section{Hospital maternidade}

Considerado como um estabelecimento de saúde especializado, esse hospital atende desde situações de planejamento sexual e reprodutivo, de pré-natal de risco, até as emergências obstétricas e ginecológicas. Com aproximadamente 250 atendimentos/dia e trinta partos/dia, é referenciado como uma 
organização de média complexidade servindo a população carente da cidade de Salvador.

Nessa instituição foram entrevistados cinco estagiários: dois do curso de enfermagem, um de fisioterapia, um de medicina e um do curso do bacharelado interdisciplinar em saúde. Os participantes tinham idade entre 21 e 30 anos, com a média de 23,4 anos. Quanto à escolaridade, estavam entre o quinto e o oitavo semestres do curso, e $60 \%$ destes se declararam cotistas.

\section{Centro de referência e diagnóstico}

Em meados do início dos anos 2000, esse estabelecimento de saúde foi criado com o objetivo de atender de forma ambulatorial e hospital dia os usuários de saúde que precisavam de atendimento às doenças sexualmente transmissíveis (DSTs). Como serviço de saúde, é considerado de média complexidade e abrange desde o atendimento médico até o serviço psicológico e de serviço social.

A média da idade dos estudantes estagiários nessa instituição foi de 23,8 anos, variando entre 22 e 26 anos de idade. Desses acadêmicos, $80 \%$ afirmaram ser cotistas. Em relação ao curso, entrevistaram-se dois estudantes de medicina, um de saúde coletiva, um de fonoaudiologia e um de enfermagem, que estavam entre o segundo e o nono períodos.

\section{Hospital geral A}

Com mais de trezentos leitos, esse hospital se classifica como de atendimento de demanda espontânea e referenciada, abrangendo diversas especialidades médicas, desde o pronto atendimento (observação hospitalar) até o serviço de traumatologia.

Os estagiários entrevistados nessa instituição estavam cursando entre o quarto e o nono semestres, com as idades variando entre 20 e 26 anos (média de 22,8). Quanto ao curso de saúde, foram entrevistados dois alunos do bacharelado interdisciplinar em saúde; os demais eram um de odontologia, um de fonoaudiologia e um de fisioterapia, com $80 \%$ desses estudantes cotistas.

\section{Hospital geral B}

Considerado como hospital de grande porte, de alta complexidade e com mais de seiscentos leitos, atende múltiplas especialidades clínicas. A emergência inclui atendimento pediátrico, adulto e obstétrico com aproximadamente quinhentos pacientes/dia.

Os cinco entrevistados nessa intituição pertenciam aos cursos de bacharelado interdisciplinar em saúde, enfermagem, fisioterapia, medicina e serviço 
social, e estavam cursando o sexto ou o sétimo semestres. A idade média variava entre 20 e 25 anos (média de 22,4), com $60 \%$ do quadro de cotistas.

Tabela 1

\begin{tabular}{|c|c|c|c|c|c|c|c|c|}
\hline \multicolumn{9}{|c|}{ Dados socioeconômicos e demográficos dos estudantes, 2015} \\
\hline Local & Estudante & Idade (anos) & Sexo & Curso & IES & Semestre & Cotista & Renda \\
\hline HM & 1 & 22 & $\mathrm{~F}$ & Bl saúde & UFBA & $5^{\circ}$ & Sim & $1-3 \mathrm{SMs}$ \\
\hline HM & 2 & 21 & $\mathrm{~F}$ & Enfermagem & Uneb & $5^{\circ}$ & Sim & $1-3 \mathrm{SMs}$ \\
\hline HM & 3 & 23 & $\mathrm{~F}$ & Fisioterapia & Uneb & $6^{\circ}$ & Não & 4-6 SMs \\
\hline $\mathrm{HM}$ & 4 & 21 & M & Medicina & UFBA & 70 & Sim & $7 \mathrm{SMs}$ \\
\hline $\mathrm{HM}$ & 5 & 30 & $\mathrm{~F}$ & Enfermagem & Uneb & $8^{\circ}$ & Não & 4-6 SMs \\
\hline CRD & 6 & 23 & M & Saúde coletiva & UFBA & $2^{\circ}$ & Sim & $1-3 \mathrm{SMs}$ \\
\hline CRD & 7 & 26 & $M$ & Medicina & UFBA & $6^{\circ}$ & Sim & 1-SMs \\
\hline CRD & 8 & 22 & $\mathrm{~F}$ & Fonoaudiologia & UFBA & $9^{\circ}$ & Sim & $1-3 \mathrm{SMs}$ \\
\hline CRD & 9 & 24 & $\mathrm{~F}$ & Medicina & UFBA & $6^{\circ}$ & Não & $7 \mathrm{SMs}$ \\
\hline CRD & 10 & 24 & $\mathrm{~F}$ & Enfermagem & Uneb & $6^{\circ}$ & Sim & $1-3 \mathrm{SMs}$ \\
\hline HGA & 11 & 26 & $\mathrm{~F}$ & Odontologia & UFBA & $9 \circ$ & Não & 4-6 SMs \\
\hline HGA & 12 & 26 & $\mathrm{~F}$ & Fisioterapia & UFBA & $6^{\circ}$ & Sim & $1-3 \mathrm{SMs}$ \\
\hline HGA & 13 & 20 & $\mathrm{~F}$ & Bl saúde & UFBA & $4^{\circ}$ & Sim & $1-3 \mathrm{SMs}$ \\
\hline HGA & 14 & 20 & $\mathrm{~F}$ & Bl saúde & UFBA & $6^{\circ}$ & Sim & $1-3 \mathrm{SMs}$ \\
\hline HGA & 15 & 22 & $\mathrm{~F}$ & Fonoaudiologia & UFBA & $8^{\circ}$ & Sim & $1-3 \mathrm{SMs}$ \\
\hline HGB & 16 & 21 & $\mathrm{~F}$ & Fisioterapia & Uneb & $6^{\circ}$ & Não & $7 \mathrm{SMs}$ \\
\hline HGB & 17 & 21 & $\mathrm{~F}$ & Bl saúde & UFBA & $6^{\circ}$ & Sim & $1-3 \mathrm{SMs}$ \\
\hline HGB & 18 & 25 & M & Medicina & UFBA & 70 & Não & $7 \mathrm{SMs}$ \\
\hline HGB & 19 & 20 & $\mathrm{~F}$ & Serviço social & UFBA & $7^{\circ}$ & Sim & 1-3 SMs \\
\hline HGB & 20 & 25 & $\mathrm{~F}$ & Enfermagem & Uneb & $6^{\circ}$ & Sim & $1-3 \mathrm{SMs}$ \\
\hline
\end{tabular}

Fonte: As autoras.

Notas:HM: hospital maternidade; CRD: centro de referência e diagnóstico; HGA: hospital geral A; HGB: hospital geral B; F: feminino; M: masculino; BI: bacharelado interdisciplinar; IES: instituição de ensino superior; UFBA:Universidade Federal da Bahia;Uneb:Universidade Estadual da Bahia; SMs: salários mínimos.

De forma geral, quando comparadas as informações do documento base do programa Permanecer SUS com os dados da pesquisa (Tabela 1), por meio da observação participante e do diário de campo, constatou-se que, mesmo entre aqueles estudantes não entrevistados, nenhum acadêmico da Universidade Católica do Salvador foi localizado. Também se observou que não houve a participação de alunos dos cursos de farmácia, nutrição e psicologia durante 
o referido período. Quanto ao aspecto demográfico, verificou-se que $80 \%$ dos estudantes (16) eram do sexo feminino. Houve predominância de acadêmicos cotistas $(70 \%-14)$, com $65 \%$ (13) da renda entre um e três salários mínimos, o que pôde ratificar uma das propostas do programa: a permanência de estudantes em vulnerabilidade econômica. Em relação à idade, a média foi de 23,2 anos, variando de 20 a 30 anos. A maioria dos estagiários $(70 \%-14)$ tem a UFBA como a universidade de origem. Acredita-se que tal evidência se deva ao fato de essa instituição ter protagonizado o início do programa. Por fim, a maioria ( $45 \%$ - nove) estava participando do estágio com mais de $50 \%$ de sua graduação concluída (sexto período), o que confirmou um dos critérios estabelecidos durante a seleção, que priorizava estudantes entre o quarto e o sexto semestres do curso.

\section{Humanização e acolhimento na atenção à saúde}

O termo humanização na saúde emergiu por volta do final da década de 1990 e início do ano 2000, diante de um contexto em que se visualizavam fragilidades na relação usuário-trabalhador de saúde e a dificuldade de concretização da integralidade da assistência. Registrou-se na $11^{\text {a }}$ Conferência Nacional de Saúde, no ano 2000, a abordagem do tema central: “Efetivando o SUS - acesso, qualidade e humanização na atenção à saúde com controle social"; e como um dos subtemas: "Fortalecimento dos princípios do SUS: o caráter público, a integralidade, a equidade e a humanização" (Brasil, 2009). Subsidiada pelas discussões dessa conferência e por outras experiências, foi então institucionalizada a Política Nacional de Humanização (PNH), em 2003, respaldada em princípios como a humanização e o acolhimento.

Conforme Deslandes (2004, p. 9-10), o termo humanização ganha significados que contemplam desde oposição à violência física ou psicológica até a "capacidade de oferecer atendimento de qualidade, articulando os avanços tecnológicos com o bom relacionamento" e também as "melhorias das condições de trabalho do cuidador e da ampliação do processo comunicacional".

A PNH considera o acolhimento como umas de suas diretrizes e se constitui como uma postura ética que implica o atendimento das queixas do paciente, a compreensão do seu protagonismo, a ativação das redes e o compartilhamento dos saberes (Brasil, 2008). Ainda no que concerne ao termo acolhimento, pode-se utilizar o discurso de um dos entrevistados para significá-lo:

O acolhimento realizado por nós se baseia na escuta da queixa do paciente, mas não somente desta, mas no processo como um todo. Aqui no Permanecer SUS não queremos saber apenas o que o trouxe ao hospital, mas escutar as angústias e entender aquela situação para realmente resolver a situação do paciente (EFIS3). 
$\mathrm{O}$ acolhimento, portanto, se configura para esse estudante como uma ferramenta do processo de trabalho responsável (Lacerda, 2009) e como dispositivo para subsidiar a relação entre usuário e profissional de saúde. Esse encontro acontece, geralmente, diante de uma relação que necessita de atendimento emergencial e por isso em situações completamente diferentes: de um lado se tem o usuário, que necessita de cuidado, não somente físico, mas também emocional; e do outro se encontra o profissional de saúde, que deve estar capacitado e preparado para atender a essa demanda. Assim, cria-se um vínculo, gerador de uma ligação afetiva e ética, que se respalda numa convivência de ajuda e respeito mútuos, baseados na humanização e no acolhimento dos cuidados de saúde (Brasil, 2008), conforme se concretiza nos discursos:

O retorno que temos é do usuário, que volta e agradece pelo simples fato de termos facilitado o seu atendimento de forma cortês e ética (EENF10).

Eles [usuários] ficam contentes com o atendimento que prestamos, mesmo que não seja a solução imediata para os seus problemas (EBIS17).

Muitos aqui são pacientes recorrentes. Estes nos procuram em últimas instâncias, mesmo porque já foram orientados por nós. Eu me lembro de um caso, de uma senhora, que me chamou 'ô, minha filha' de uma forma tão doce, que eu parecia mesmo alguém da família dela, que aquilo despertou em mim um sentimento de respeito e de poder de ajuda, que se concentrava em minhas mãos. Eu acho que a gente da saúde deve pensar assim, uma relação mútua, de interação, de ajuda e de interesse em estar aberto e solícito (EBIS1).

Palavras, gestos e atitudes são formas de comunicação no processo do relacionamento humano. No discurso aqui apresentado, o estudante descreveu como uma simples frase o tocou, fez despertar nele um sentimento de potencialidade e de respeito diante do sofrimento humano. É nessa perspectiva que a PNH se estrutura em sensibilizar os profissionais de saúde acerca do relacionamento interpessoal, com base na reflexão sobre suas ações e prestação de serviço.

A humanização precisa vir de forma natural, porque infelizmente na universidade a gente vê muita teorização. Então, o Permanecer SUS é uma forma de compreendermos e encarar o sistema, não simplesmente na burocratização, mas na forma de cuidar do outro, de dar atenção e ouvir. Eu indico esse estágio para todos os estudantes e até acredito que deveria ser curricular, porque na universidade estudamos muito pouco sobre a relação com os usuários (EFIS16).

O estudante de fisioterapia aqui citado destacou a fragilidade encontrada no ensino e a questão da falta de preparo para o sentido simples do 
atendimento: o de ouvir, de se interessar pelo usuário e não unicamente pela patologia que o acompanha. Além disso, problematizou um dos motivos da implantação da PNH: o pouco interesse e conhecimento na graduação dos profissionais de saúde diante das questões sociais e subjetivas dos pacientes. Essa assertiva pôde ainda ser evidenciada no discurso: “a principal dificuldade no acolhimento são os profissionais já atuantes, pois acredito que não tiveram uma oportunidade como esta que estou tendo" (EFIS12), corroborando Ferreira (2005), autora que considera que esse despreparo e (des)formação dos profissionais culminam na fragilização das práticas de saúde. Ao mesmo tempo, outro discurso, a seguir, reforçou mais uma vez a necessidade de mudanças na educação superior em saúde:

Na universidade a gente aprende a ouvir o paciente, só que temos um critério estabelecido para ouvir. Por exemplo: direcionamos o paciente para o que queremos ouvir. Desenvolvemos as perguntas na anamnese, na história do paciente, focando na definição do diagnóstico, e muitas vezes deixamos de lado o psicossocial, que sabemos que influencia. Então, assim, ajudou e está ajudando muito [sobre o Permanecer SUS] na minha formação. Eu consigo hoje entender o que é acolher e fazer uma escuta qualificada. (...) É, eu acho que mudei muito! (EMED7).

Estabelecer prioridades nas práticas de ensino já é sabido há certo tempo. Porém, o grande desafio exposto foi o de confrontar as novas práticas com a realidade social diante de um sistema vitimado pela globalização e pela otimização dos resultados. Entender, portanto, a formação do pessoal de saúde é ancorar em conceitos que priorizem um atendimento integral, mais humano e capaz de assistir todos em suas necessidades mais distintas possíveis. Por isso, o Permanecer SUS se fundamenta em conceitos, princípios e dispositivos que norteiam seus resultados na mudança do cenário em que se encontra a saúde, impulsionando usuário, trabalhadores e gestores como protagonistas do SUS.

\section{Construindo redes}

A Rede de Atenção à Saúde (RAS) é um conjunto de serviços de saúde e arranjos organizativos de ações em diversos níveis de complexidade que deve garantir a integralidade da assistência.

O objetivo da RAS é promover a integração sistêmica, de ações e serviços de saúde, com provisão de atenção contínua, integral, de qualidade, responsável e humanizada, bem como incrementar o desempenho do sistema, em termos de acesso, equidade, eficácia clínica e sanitária; e eficiência econômica (Brasil, 2010). 
Atualmente, em que pesem importantes avanços alcançados pelo SUS, destaca-se que ainda existem dificuldades em superar a segmentação existente nas ações e nos serviços de saúde. O cenário brasileiro fundamenta-se no modelo de atenção curativa, caracterizando-se por intensa fragmentação de ações e programas de saúde, o que leva à insuficiência para administrar as necessidades sanitárias atuais. Mendes (2010) ressalta que os sistemas organizados de forma fragmentada tendem a ser considerados um desastre sanitário e econômico em todo o mundo, corroborando a Organização Mundial da Saúde (World Health Organization, 2000) - a qual reitera, no Relatório Mundial da Saúde, em 2000, mesmo que indiretamente, que a fragmentação dos serviços de saúde pode levar a resultados negativos e, consequentemente, desarticular a eficiência e a promoção da equidade. Por isso, Santos e Andrade (2011) consideram que as redes de saúde devem ser direcionadas por interconexões entre os serviços, resultando em interação deles, porém sem perder a autonomia, que é particular de cada setor de saúde.

O Permanecer SUS tenta dar continuidade à atenção ao usuário e tem como um dos seus objetivos principais disponibilizar informações acerca da Rede de Atenção à Saúde, de modo a facilitar a compreensão do sistema, como se observa no discurso do estudante: "quando estamos de fora imaginamos um SUS ruim, e na verdade não é. O que falta é mais investimento, uma melhor administração e articulação entre os setores locais" (EENF2).

Por isso, observa-se que um dos obstáculos enfrentados pelos estudantes que participaram do estágio Permanecer SUS era a desarticulação existente entre os diversos setores da saúde, levando às dificuldades de operacionalizar a assistência integral, muitas vezes por questões estruturalmente rígidas. Estas se tornam barreiras para a execução dos serviços, a exemplo da espera da regulação para transferência de paciente e disponibilidade em unidades de saúde para realizar exames de alta complexidade.

Nós buscávamos dentro da rede do hospital uma maneira de dar resolutividade à demanda do paciente. Quando extrapolava a rede do hospital, buscávamos orientar o usuário para procurar o local correto, a quem procurar, e quando extrapolava essa demanda, buscávamos outros meios, através de outros profissionais mais experientes que sabiam orientar um pouco melhor (EENF20).

Eu auxilio como um elo de comunicação entre usuário e o profissional, porque muitas coisas aconteciam e o profissional não informava o usuário. Muitas coisas sobre a saúde do paciente, o que estava acontecendo para não ter feito o exame, o porquê da demora da transferência, informações das normas do hospital, burocracia da unidade, e isso tudo influencia diretamente no bem-estar do paciente (ESSO19). 
Conforme Shimizu (2013), as redes são percebidas pelos estudantes como capazes de possibilitar a continuidade do cuidado e o alcance da integralidade ao usuário. Porém, limitados pela desarticulação entre os setores de saúde da unidade e pela incompreensão de alguns profissionais da área, os estagiários são confrontados diante da dicotomia: necessidade de articular as redes e desordenação das RASs no SUS.

Tem horas que paro e penso se realmente aquilo que estamos estudando e aprendendo no Permanecer SUS é o ideal. Tentamos dar o melhor de nós ao usuário, mas acabamos freados por alguma coisa, seja pela má vontade do profissional ou se é pelo desconhecimento da necessidade de articulação entre os serviços. Mas estamos aqui para isso, não é? Ainda temos muito que aprender a desatar os nós e fazer a articulação em redes (ESCO6).

Reitera-se, portanto, que a compreensão das RASs depende das ações que são implementadas no ordenamento da formação (Lima, 2009). Ora, se não há estímulo por parte das instituições formadoras em conceber o sentido do acionamento das redes, dificultar-se-ão o entendimento, a coesão e a convergência dos interesses dos estudantes pelo significado e importância das redes de atenção. Por isso, é necessário que as falhas detectadas no atual sistema possam ser transformadas, na tentativa de promover atendimento de qualidade aos usuários, garantindo-lhes os princípios propostos pelo SUS: equidade, universalidade, integralidade, participação e controle social.

\section{Interdisciplinaridade}

Gattás (2006) entende a interdisciplinaridade como uma estratégia que permeia de forma sinérgica e interacional as diferentes especialidades do campo da saúde. Por meio do reconhecimento da necessidade de se considerar a totalidade do ser humano e o ambiente em sua volta, se opõe ao conhecimento disciplinarizado e à divisão de saberes em conteúdos, buscando a integração entre as áreas em benefício da integralidade da assistência do usuário de saúde. “Nesse sentido, a interdisciplinaridade não configura como uma teoria ou método novo: ela é uma estratégia para compreensão, interpretação e explicação de temas complexos" (Minayo, 2010, p. 437). Assim, a interdisciplinaridade é incluída como uma das diretrizes da formação de recursos humanos em saúde, uma vez que se presencia a continuação de um ensino centrado na biomedicina, no recorte do indivíduo e no trabalho individualizado. Portanto, a interdisciplinaridade atende ao conceito ampliado de saúde, tema complexo que vai além do processo saúde-doença e exige profissionais mais preparados e imersos nos determinantes sociais e eco- 
nômicos do processo do cuidar, direcionando a atenção para a promoção da saúde e para a transformação social (Gattás, 2006).

De modo a atender a Política Nacional da Reorientação da Formação do Pessoal de Saúde, a PEGTES ratifica a importância da prática multidisciplinar e do trabalho em equipe, por meio da organização interdisciplinar dos processos educativos e de trabalho. Ao direcionar, portanto, seus esforços para o rompimento do trabalho isolado e da fragmentação das ações nos serviços de saúde, prioriza a formação, desde a graduação, de profissionais que estejam comprometidos com a integralidade da assistência. Dessa forma, o Permanecer SUS, como programa da PEGTES, orienta e direciona suas ações com foco na interdisciplinaridade e na resolução em conjunto das ações de saúde, como se pode analisar no discurso do estudante:

Nós trabalhamos aqui em equipe. Quando dá para fazermos o atendimento em dupla fica até mais legal, mas nem sempre acontece. Devido ao fluxo ser muito grande, mas no final do dia temos um momento de discussão e de reflexão, todos juntos. Cada um traz algum caso que lhe chamou mais atenção e discutimos em grupo. É engraçado, cada um tenta trazer para seu lado, como se diz: puxa sardinha para o seu lado [risos], mas acaba que entendemos que é isso que faz crescer, um trabalho em equipe, cada um trazendo sua experiência e seu saber para a construção do coletivo e do bem do usuário. É muito, muito bom! (EBIS13).

Os estudantes de alguns cursos relataram que na academia pouco ou nunca se fala sobre a interdisciplinaridade. Quando se tem alguma atividade, dividem a sua parte e cada um a faz de forma separada, não há uma sinergia, não há encontro para discutir o fato:

Na universidade a gente não trabalha em equipe, cada um faz a sua parte (EODO11).

Não, não há integração entre as áreas do conhecimento (EMED18).

Para lhe ser sincera, eu só fui saber o que era interdisciplinaridade com o Permanecer SUS (EFON15).

Muito bom esse estágio [sobre o Permanecer SUS]. É fantástica a discussão dos casos dos usuários em equipe (...) é, isso não temos na universidade, estudamos o paciente apenas com a visão da enfermagem (EENF5).

A principal dificuldade que encontramos aqui no Permanecer SUS é a integração com alguns profissionais. Alguns não nos olham com bons olhos, eu já até ouvi de um falar: “Aqui é muita correria, não temos tempo de discutir com os outros 
profissionais não, se formos fazer isso, não daremos conta do trabalho." Eu acho que podemos mudar isso, mas se houver interesse e vontade de trabalhar em equipe e logicamente se houver mais estágios como esse, porque na universidade é difícil (ESSO19).

Com os discursos apresentados, nota-se ainda que a formação dos profissionais de saúde é desconectada da proposta da formação plural e humanística, com a qual a interdisciplinaridade está em total sincronia. Porém, vale ressaltar que ela "não pode ser um remédio para todos os males" (Gattás, 2006, p. 90), uma vez que depende da disposição das especialidades (áreas) em participar dessa discussão e do distanciamento do modelo cartesiano e biomédico da saúde.

Morin (1999) considera que os variados aspectos de uma realidade humana são complexos, por isso só adquirirão sentido se forem interconjugados por meio da ligação com a realidade. Nesse sentido, é justificável que a formação em saúde seja direcionada para a integração de experiências interdisciplinares, na perspectiva da integralidade, pois essas são contrárias à fragmentação do ser humano e, consequentemente, podem oferecer maior "reorganização dos serviços de saúde e análise crítica dos processos de trabalho" (Ghizoni, Arruda e Tesser, 2010, p. 831) ao compartilhar ações de responsabilidade essenciais para a formação e a prática (Trevisan et al., 2014).

Portanto, a experiência interdisciplinar do Permanecer SUS não busca excluir o conhecimento das disciplinas, mas sim integrá-lo no enriquecimento da compreensão das ações de saúde, a fim de que seja ampliada a eficácia da intervenção para o benefício dos usuários dos serviços de saúde.

\section{Considerações finais}

Em vista dos argumentos apresentados pelos estudantes, percebeu-se que o Permanecer SUS oportuniza diálogo, ressignificação da formação e comunicação entre os integrantes do programa e futuros profissionais de saúde, uma vez que, por meio de uma experiência prática e inovadora, deixa os muros da universidade e se encontra diante da sociedade, com o objetivo principal de oferecer melhores condições de assistência ao usuário do SUS.

Questões sobre a relação entre humanização, acolhimento, redes e interdisciplinaridade foram discutidas e evidenciadas pelos acadêmicos em total sincronia com as diretrizes do Permanecer SUS. No que tange à humanização e ao acolhimento dos serviços de saúde, os discursos dos estudantes atestaram a importância de uma formação que seja direcionada nessas perspectivas e intensificada na produção do cuidado. 
A discussão sobre a construção de redes foi evidenciada na fala dos estagiários sobre as dificuldades, por parte dos profissionais de saúde já atuantes da unidade, em compreender e efetivar a comunicação entre as RASs, o que dificulta o processo de resolutividade das ações no SUS. Ao mesmo tempo, os estudantes conseguiram entender a necessidade de construção e ativação das redes, demonstrando maturidade e responsabilidade em relação à integralidade da assistência.

Acerca da interdisciplinaridade, observou-se que foram relacionados obstáculos para a efetivação do programa, considerando-se a necessidade do trabalho interdisciplinar para o Permanecer SUS. Houve discursos de estudantes que apontaram a importância de mudanças significativas nas instituições formadoras, ou seja, no currículo dos cursos de saúde ainda ancorados em bases disciplinares e que não favorecem a complexidade do cuidado com seres humanos.

Apesar das mudanças já vivenciadas na formação do profissional de saúde, muitas ainda foram as críticas verberadas, principalmente contra o modelo hospitalocêntrico hegemônico no ensino, com base no qual a população crê que a saúde se faz com exames de alta tecnologia ou prescrição de medicamentos. Assim, acredita-se que tal conceito não será facilmente extinto se não houver sensibilização de diversos atores, incluindo estudantes, docentes, comunidade e gestores. Estes últimos, por sua atuação política e administrativa, configuram-se como agentes essenciais e capazes de propor novos projetos e programas direcionados para a promoção e a reorientação da educação do pessoal de saúde, visando à melhoria do trabalho nas organizações.

Nessa perspectiva, o programa de estágio Permanecer SUS age possibilitando uma reorientação da formação dos futuros profissionais de saúde e evidencia outras ferramentas, a exemplo da escuta ampliada e do acolhimento, capazes de fazer um atendimento integral e de qualidade - logicamente sem descartar a possibilidade e o uso de práticas assistencialistas, quando necessárias ao restabelecimento da saúde do usuário.

Portanto, o programa Permanecer SUS proporciona reflexões críticas e contribui para a transformação da formação em saúde, reafirmando a importância da relação entre teoria e prática, como vivência que possibilita o compromisso social, a ética e a autonomia do sujeito. Ao mesmo tempo que a efetividade do programa é evidenciada, aponta-se para o engajamento, por meio da formação interdisciplinar, de futuros profissionais mais comprometidos com a saúde pública, consoante os princípios do SUS.

Finalmente, diante das contribuições significativas e expostas à formação acadêmica em saúde, a experiência do Permanecer SUS pode auxiliar na construção de novas propostas que possibilitem a vivência de estudantes em campo de estágio priorizando a temática da Política Nacional de Humanização, na perspectiva da resolubilidade das ações de saúde. 


\section{Colaboradores}

Wilton Nascimento Figueredo participou da coleta de dados, escrita e revisão do artigo. Renata Meira Véras participou da revisão crítica. Não há conflito de interesses.

Resumen Este artículo tuvo como objetivo analizar las contribuciones del Permanecer SUS, programa de la Secretaría de Salud del Estado de Bahía, Brasil, para la formación de los estudiantes y futuros profesionales de la salud. La investigación tuvo un abordaje cualitativo en la perspectiva de la etnografía institucional. Los dados se obtuvieron mediante entrevistas semiestructuradas con veinte estudiantes de la salud participantes en el programa en 2015. Los resultados señalaron la efectividad del Permanecer SUS. Se constató la valorización del trabajo en equipo en forma interdisciplinaria, la desarticulación de redes y la necesidad de abordajes en la formación de esos estudiantes acerca de la humanización y de la acogida. En contrapartida, se observó deficiencia en la comprensión de la red por parte de los profesionales de la salud que ya actuaban en la unidad, lo que puede dificultar una asistencia integral. Se concluyó que el programa Permanecer SUS permite el diálogo, la resignificación de la formación y la comunicación entre los integrantes y futuros profesionales de la salud, estimulando a los estudiantes a trabajar en redes en el Sistema Único de Salud.

Palabras clave educación en salud; acogida; humanización de la asistencia; educación superior.

\section{Notas}

1 Universidade Federal da Bahia, Escola de Enfermagem, Salvador, Bahia, Brasil.

<enfer.willfigueredo@gmail.com>

Correspondência: Avenida Sete de Setembro, 2.847, apartamento 302-A, Barra, CEP 40130-001, Salvador, Bahia, Brasil.

2 Universidade Federal da Bahia, Instituto de Humanidades, Artes e Ciências Milton Santos, Salvador, Bahia, Brasil.

$<$ renatameiraveras@gmail.com>

3 Este artigo é resultado de parte da dissertação de mestrado intitulada Permanecer SUS: contribuições para a formação em saúde (Figueredo, 2015), defendida no Programa de Pós-Graduação em Estudos Interdisciplinares sobre a Universidade, da UFBA. A pesquisa foi financiada pela Fundação de Amparo à Pesquisa do Estado da Bahia (Fapesb), e o primeiro autor obteve bolsa da Coordenação de Aperfeiçoamento de Pessoal de Nível Superior (Capes). 


\section{Referências}

ANGROSINO, Michael. Etnografia e observação participante. Porto Alegre: Artmed, 2009.

BAHIA. Secretaria da Saúde. Documento base do Programa Permanecer SUS. Salvador: Sesab, 2008.

BAHIA. Governo do Estado. Secretaria da Saúde do Estado da Bahia. Política Estadual de Gestão do Trabalho e Educação na Saúde do SUS Bahia. Salvador: Superintendência de Recursos Humanos da Saúde, 2012.

BOWES, Érica C. S. Permanecer SUS: acolhendo sujeitos e histórias no caminhar da formação profissional em saúde. 56 fls. Dissertação (Mestrado Profissional em Saúde Coletiva) - Instituto de Saúde Coletiva, Universidade Federal da Bahia, Salvador, 2014.

BRASIL. Constituição da República Federativa do Brasil. Brasília: Senado Federal, 1988.

BRASIL. Lei n. 8.080, de 19 de setembro de 1990. Dispõe sobre as condições para a promoção, proteção e recuperação da saúde, a organização e o funcionamento dos serviços correspondentes e dá outras providências. Brasília: Senado Federal, 1990. Disponível em: <www.planalto.gov.br/ccivil_03/leis/ L8080.htm>. Acesso em: 18 jun.2016.

BRASIL. Núcleo Técnico da Política Nacional de Humanização. Política Nacional de Humanização - HumanizaSUS: documento base para gestores e trabalhadores do SUS. Brasília: Ministério da Saúde, 2008. Disponível em:<http://bvsms.saude.gov.br/bvs/ publicacoes/documento_base.pdf $>$. Acesso em: 10 mar. 2014

BRASIL. Conselho Nacional de Secretários de Saúde. As Conferências Nacionais de Saúde: evolução e perspectivas. Brasília: Conass, 2009. Disponível em: <www.conass.org.br/ conassdocumenta/cd_18.pdf $>$. Acesso em: 18 jun. 2016.

BRASIL. Portaria n. 4.279, de 30 de dezembro de 2010: estabelece diretrizes para a or- ganização da Rede de Atenção à Saúde no âmbito do Sistema Único de Saúde (SUS). Disponível em: <http://bvsms.saude.gov.br/ bvs/saudelegis/gm/2010/prt4279_30_12_ 2010.html>. Acesso em: 18 jun. 2016.

BRASIL. Conselho Nacional de Secretários de Saúde. A gestão do trabalho e da educação na saúde. Brasília: Conass, 201 la. Disponível em: <http://bvsms.saude.gov.br/bvs/ publicacoes/para_entender_gestao_sus_v. 9.pdf>. Acesso em: 18 jun. 2016.

BRASIL. Ministério da Saúde. Secretaria de Gestão do Trabalho e da Educação em Saúde. SGTES: políticas e ações. Brasília: Ministério da Saúde, 2011b. Disponível em: <http:// docplayer.com.br/1248040-Ministerio-dasaude-secretaria-de-gestao-do-trabalho-eda-educacao-na-saude-sgtes-politicas-eacoes.html>. Acesso em: 18 jun. 2016.

BRASIL. Ministério da Saúde. Conselho Nacional de Saúde. Resolução CNS n. 466, de 12 de dezembro de 2012. Estabelece diretrizes e normas regulamentadoras de pesquisa envolvendo seres humanos. Brasília: Ministério da Saúde, 2012. Disponível em: $<$ http:// bvsms.saude.gov.br/bvs/saudelegis/cns/2013/ res0466_12_12_2012.html>. Acesso em: 18 jun.2016.

CAMPBELL, Marie; GREGOR, Frances. Mapping social relations: a primer in doing institutional ethnography. Ontario: Garamond Press, 2008.

CARVALHO, Yara M.; CECCIM, Ricardo B. Formação e educação em saúde. In: CAMPOS, Gastão W. S. et al. (orgs.). Tratado de saúde coletiva. Rio de Janeiro: Hucitec, 2012. p. $137-170$.

DESLANDES, Suely F. Análise do discurso oficial sobre a humanização da assistência hospitalar. Ciência \& Saúde Coletiva, Rio de Janeiro, v. 9, n. 11, p. 7-14, 2004. Disponível em: <www.scielo.br/pdf/csc/v9nl/19819.pdf >. Acesso em: 10 mar. 2014. 
DEVAULT, Marjorie L.; McCOY, Liza. Institutional ethnography, using interviews to investigate ruling relations. In: GUBRIUM, Jaber F.; HOLTEINS, James (orgs.). Handbook of interview research. Thousand Oaks/London: Sage, 2002. p. 381-395.

FERREIRA, Jaqueline. O Programa de Humanização da Saúde: dilemas entre o relacional e o técnico. Saúde e Sociedade, São Paulo, v. 14, n. 3, p. 111-118, 2005. Disponível em: <www. scielo.br/pdf/sausoc/v14n3/07.pdf >. Acesso em: 10 mar. 2014.

FIGUEREDO, Wilton N. Permanecer SUS: contribuições para a formação em saúde. 75 fls. Dissertação (Mestrado Acadêmico em Estudos Interdisciplinares sobre a Universidade) Instituto de Humanidades Artes e Ciências Prof. Milton Santos, Universidade Federal da Bahia, Salvador, 2015. Disponível em: $<$ https://repositorio.ufba.br/ri/bitstream/ri/ 18227/1/Disserta \%C3\%A7\%C3\%A30\%20 Wilton \%20Figueredo.pdf $>$. Acesso em: 18 jun. 2016.

FOUCAULT, Michel. Arqueologia do saber. Rio de Janeiro: Forense, 1986.

GATTÁS, Maria L. B. Interdisciplinaridade: formação e ação na área de saúde. Ribeirão Preto: Holos, 2006.

GHIZONI, Angela C.; ARRUDA, Marina P.; TESSER, Charles D. A integralidade na visão dos fisioterapeutas de um município de médio porte. Interface: Comunicação, Saúde, Educação, Botucatu, v. 14, n. 35, p. 825-837, 2010. Disponível em: <www.scielo.br/pdf/ icse/2010nahead/aop2410.pdf > . Acesso em: 11 jun. 2014.

LACERDA, Kamile M. Acolhimento nas emergências públicas de saúde: o caso da tecnologia 'Permanecer SUS' no Hospital Geral Roberto Santos. 59 fls. Monografia (Especialização em Gestão de Tecnologias em Saúde) - Instituto de Saúde Coletiva, Universidade Federal da Bahia, Salvador, 2009.

LIMA, Jamile O. Uma estratégia para articulação ensino-serviço no SUS-BA: a rede de integração da educação e trabalho na saúde. 143 fls. Dissertação (Mestrado Profissional em Gestão do Trabalho e da Educação na Saúde) - Escola Nacional de Saúde Pública Sergio Arouca, Fundação Oswaldo Cruz, Rio de Janeiro, 2009.

MATTOS, Ruben A. A integralidade na prática (ou sobre a prática da integralidade). Cadernos de Saúde Pública, Rio de Janeiro, v. 20, n. 5, p. 1.411-1.416, 2004. Disponível em: <www.scielosp.org/pdf/csp/v20n5/37.pdf>. Acesso em: 11 jun. 2014.

MENDES, Eugênio V. As redes de atenção à saúde. Ciência \& Saúde Coletiva, Rio de Janeiro, v. 15, n. 5, p. 2.297-2.305, 2010. Disponível em: $<$ www.scielo.br/pdf/csc/v15n5/v15n5a05. pdf>. Acesso em: 4 abr. 2014.

MINAYO, Maria C. S. Disciplinaridade, interdisciplinaridade e complexidade. Emancipação, Ponta Grossa, v. 10, n. 2, p. 435-442, 2010. Disponível em: <www.revistas2.uepg. br/index.php/emancipacao/article/view/ 1937/1880>. Acesso em: 11 jun. 2014.

MORIN, Edgar. A cabeça bem-feita: repensar a reforma, reformar o pensamento. Rio de Janeiro: Bertrand Brasil, 1999.

PINTO, Isabela C. M.; TEIXEIRA, Carmen F. Formulação da Política de Gestão do Trabalho e Educação na Saúde: o caso da Secretaria Estadual de Saúde da Bahia, Brasil, 2007-2008. Cadernos de Saúde Pública, Rio de Janeiro, v. 27, n. 9, p. 1.777-1.788, 2011. Disponível em: <www.scielo.br/pdf/csp/v27n9/11.pdf>. Acesso em: 10 mar. 2014.

SANTOS, Lenir; ANDRADE, Luiz L. O. M. Redes interfederativas de saúde: um desafio para o SUS nos seus vinte anos. Ciência \& Saúde Coletiva, Rio de Janeiro, v. 16, n. 3, p. 1.671-1.680, 2011. Disponível em: <www. scielo.br/pdf/csc/v16n3/02.pdf>. Acesso em: 25 abr. 2014.

SHIMIZU, Helena E. Percepção dos gestores do Sistema Único de Saúde acerca dos desafios da formação de redes de atenção à saúde no Brasil. Physis: Revista de Saúde Coletiva, 
Rio de Janeiro, v. 23, n. 4, p. 1.101-1.122, 2013. Disponível em: <www.scielo.br/pdf/ physis/v23n4/05.pdf>. Acesso em: 11 jun. 2014.

TREVISAN, Danilo D. et al. Formação acadêmica e a prática profissional de enfermagem: interfaces para reflexão. Revista Baiana de Saúde Pública, Salvador, v. 38, n. 1, p. 155-162, jan./mar. 2014. Disponível em: < http://inseer. ibict.br/rbsp/index.php/rbsp/article/viewFile/ 737/pdf_473>. Acesso em: 11 jun. 2014.
VÉRAS, Renata M.; MORAIS, Fátima R. R. Coletando dados na etnografia institucional. In: VÉRAS, Renata M. (org.). Introdução à etnografia institucional. Salvador: Edufba, 2014. p. 41-58.

WORLD HEALTH ORGANIZATION (WHO). The world health report 2000: health systems improving performance. Geneva: WHO, 2000. Disponível em: <www.who.int/whr/2000/en> . Acesso em: 4 abr. 2014.

Recebido em 18/08/2014

Aprovado em 17/02/2016 